\title{
The Apple in Paradise
}

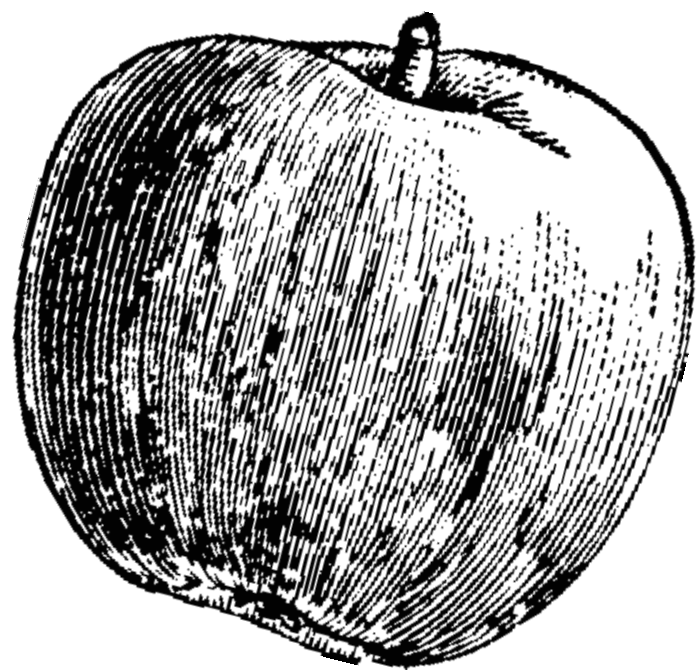

M iklos Faust

$\mathrm{n}$ the Christian mythology, the first human beings placed into Paradise by God committed sin by eating the fruit of the forbidden tree and were punished with hardships in life. N owadays, the forbidden tree is thought to be an apple tree. It is not known how or when the apple became associated with this Christian belief. This paper compiles the available evidence on the subject.

\section{The origin of Paradise}

The English word "paradise" is a transliteration of the old Persian word pairidaeza, referring to a walled garden. Cyrus the Younger (424-401 BC), a Persian king, called his walled-in garden pairidaeza, which is a simple combination of pairi (around) and daeza (wall). Pairidaeza comes to us through Xenophon, the Greek writer and historian, who heard it in 401 BC in Persia, where he fought with Greek mercenaries. Xenophon used the Greek word "paradeisoi" for garden (Lord, 1970). This became the Latin paradisus, and first appeared in M iddle English as paradis in 1175 (O xford Dict., 1933). 
The idea of Paradise as a garden is much older than the word itself. Since the beginning of history, or perhaps prehistory, so cieties shared the common concept of Paradise as the ideal garden, a secure, everlasting place. Theconcept of $P$ aradiseremained even though societies that adhered to it have disappeared. A poem on one of the oldest Sumerian cuneiform tablets (ca $3500 \mathrm{BC}$ ) describes such a place. According to this verse: "D ilmun" was a land that was pure and clear and bright, whose inhabitantsknew neither sickness, violence nor aging, but had no fresh water. Through the Sumerian gods' intervention, D ilmun was transformed into a mythical garden with fruit trees, green fields, and meadows" (Kramer, 1956), and became what today we would call Paradise.

The Paradise myth continued. In the 27th century $B C$, the Sumerian city state of E rech (Warka, I raq) was ruled by G ilgamesh. The myth of an immortal garden is repeated on Babylonian tablets bearing the "E pic" of Gilgamesh (Barondes, 1962). According to this Epic: There was an immortal garden where stood a tree with a golden trunk. I t was the Tree of $L$ ife, and, once discovered, could confer immortality, but discovery was not easy. Gilgamesh sought immortality but his tree was "hidden," guarded by monsters. $\mathrm{He}$ could never discover it and remained mortal (Cirlot, 1962).

The E pic was popular and widely known throughout the ancient world and influenced the folk tales of later civilizations (M oynihan, 1979). Two thousand years later, the holy works of the Persian prophet Zarathustra (Greek name: Zoroaster), who gained prominence in the 6 th to 4 th centuries $B C$, promised a garden, complete with a pleasure pavilion filled with fruit and fragrant flowers with paths of burnished gold. The E pic was also familiar to the J ews during their Babylonian captivity prior to their release by Cyrusthe G reat (600529 вс) in 538 вс (M oynihan, 1979). In the Old Testament, the H ebrew word "pardes" from the O Id Persian pairidaeza, means garden. It was in the G reek translation of the O Id Testament-with itsuse of theword paradei sos for garden - that Paradise became identified with the $\mathrm{G}$ arden of Eden.

\section{Paradise as more than one location}

Throughout the Bible, the earthly Paradise became identified with $\mathrm{H}$ eaven, remote and unobtainable, thus acquiring the transcendental image dominant in Christian tradition (M oynihan, 1979). The sacred vision of the $G$ arden of Paradise varies from a single place of total happiness to several gardens of varying degrees of happiness. In the $\mathrm{N}$ ew
Testament, Paul refers to a man caught up in the "third heaven" of Paradise (C orinthians II 12:2-4). The Paradise promised in the Koran consists of several terraces of gardens, each more splendid than the last (Koran) (there are about 120 references to gardens in the Koran).

\section{The place of the tree in Paradise}

In the archaic Mesopotamian civilizations, plants and treeswere believed to contain a divine presence. The Epic of Gilgamesh mentioned the "Tree" in the immortal garden. $O$ ther early Sumerian tablets often illustrate the exalted position of the Tree. O $\mathrm{n}$ one such tablet, the mystical H uluppu tree was uprooted by the south wind and carried by the waters of the Euphrates until the Goddess of Love and Fertility seized the tree in her hand (M oynihan, 1979). The Koran (13:28) mentions the Tuba tree in Paradise. In the U phanishads of ancient I ndia, the C osmic tree is depicted as an inverted tree with its roots in $\mathrm{H}$ eaven (M oynihan, 1979). M esopotamian settlers believed that the moon brought relief from therelentlesssun, and depicted themoon as atree atop themountain of sky. I I I ndia, the M oon Treewas pictured as a peepul tree (Ficus religiosa). In Persia, the M oon Tree was drawn as a conifer-possibly a cypress- that came to symbolize immortality in Persian culture (M oynihan, 1979). TheSassanian Treof Life (Sassanid dynasty ruled Persia from 226 AD until the M ohammedan conquest in $641 \mathrm{AD}$ ) was somewhat similar to a giant floral motif depicted on the D ome of Rock in Jerusalem (G rabar, 1959). Throughout history, the Tree is depicted as one of the most essential of traditional symbols. O ften the symbolic tree is of no particular genus, although oak was a sacred tree to the Celts, ash to the Scandinavians, and the fig to the Indians (Cirlot, 1962). The tree also has been reduced to its essentials in ichnography. The cross often is depicted in the Christian ichnography as tree- "Tree of Life" (Cirlot, 1962).

\section{The tree in the Bible}

At the most primitive level, there are the "Tree of Life" and the "Tree of Death" (Knappe, 1952). Thus, we have to consider a two-tree symbolism. We can find such symbolism in the Bible. In Paradise, there were the Tree of $L$ ife and the Tree of Knowledge of Good and Evil. Both were placed in the Garden of Eden.

The old Testament's Book of Genesis contains two accounts of the creation of Adam. In the first version (Genesis 1:26-30), the creation took 6 days and mankind is

Theidea of
Paradiseas
a garden ismuch
older than the
word itself. Since
the beginning of
history, or per-
haps prehistory,
societies shared
the common
concept of
Paradise asthe
ideal garden, a
secure, ever-
lasting place.


Fig. 1. (a) Adam and Eve depicted in an early French manuscript. (b) Adam and Eve depi cted on a sarcophagus (c) R oman composition of the Fall in Paradise created on the 6 th day. $M$ an is made in the image of God, and is given dominion over all the plants and animals of the earth. In the second version ( $G$ enesis 2:7-25), man is created from the dust of the earth, and placed as a caretaker in a garden situated in Eden, planted with all kinds of trees. $M$ an ispermitted to eat of the fruit of all of the trees, with the exception of one, known as the "T ree of Knowledge of Good and Evil," the fruit of which he may not eat under penalty of death. From one of his ribs, woman was made to be a helpmate to Adam. Through the serpent, who assured Eve that she and Adam would not die, the woman isbeguiled into eating the fruit of the forbidden tree and inducing Adam to eat it also. The first consequence of their act is the realization of their nakedness, and they made aprons of fig leaves for themselves. Then God banished them from the Garden.

\section{Tree of Paradise as apple}

In 1667, Milton, in "Paradise Lost," described a vision of Paradise as having the "goodliest Trees laden with fairest Fruit" (U nderwood, 1950). In the early Christian period, the illustration of the serpent seems to be more important than the illustration of the tree. In an illustration, taken from "Biblia cum Figuris" (located in Bibl. N at., Paris) (D idron, 1965), Adam and Eve are tempted by the serpent. The serpent is a two-headed hydra and is twisted on a nondescript tree (Fig. 1a). Although Adam and Eveappear to hold afruit, thefruitsaretoo small to bean apple. Thesame theme continues on a sarcophagus located in the Vatican M useum (Didron, 1965) (Fig. 2b). The serpent appears as a hydra with a dog's head tempting Adam and $E$ ve. The tree is nondescript, and Adam and Eve hold fig leaves. There are no fruits in the picture.

In a Roman composition (Fig. 1c), the serpent, having the head of a fish, still continues to have the dominant role in an illustration involving Adam and $E$ ve, but the tree is still highly stylistic (C irlot, 1962). In an 11th century composition, God points to the forbidden tree with one hand and to the animals over whom Adam was given dominion with the other (Prest, 1981). The emphasis in this composition is on illustrating the water that was supposedly plentiful in Paradise. The symbol of water is around the tree, as well as among the animals. Thetreeisunidentifiable.

Illustrations of Adam and Eve were not
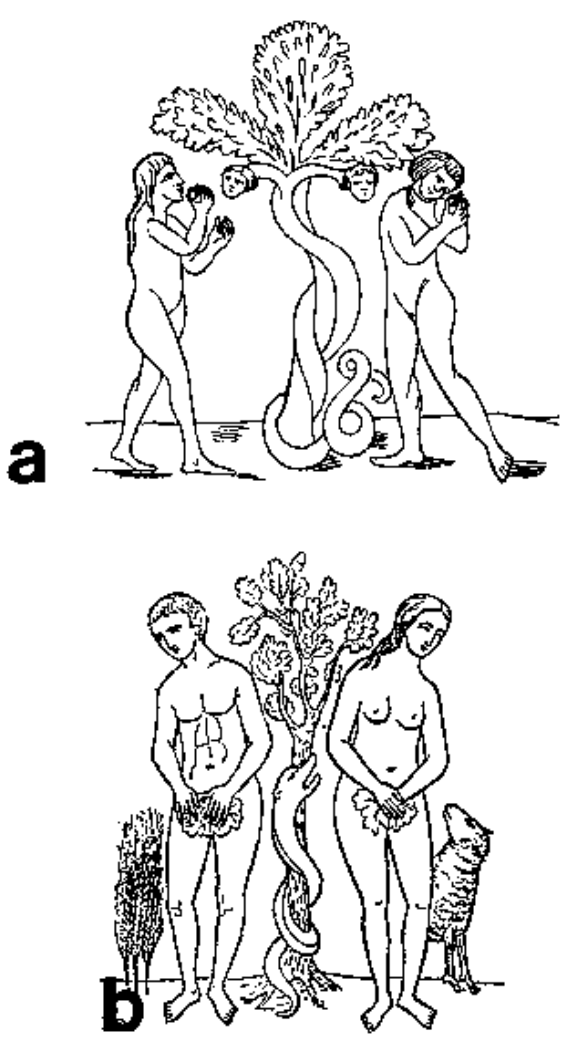

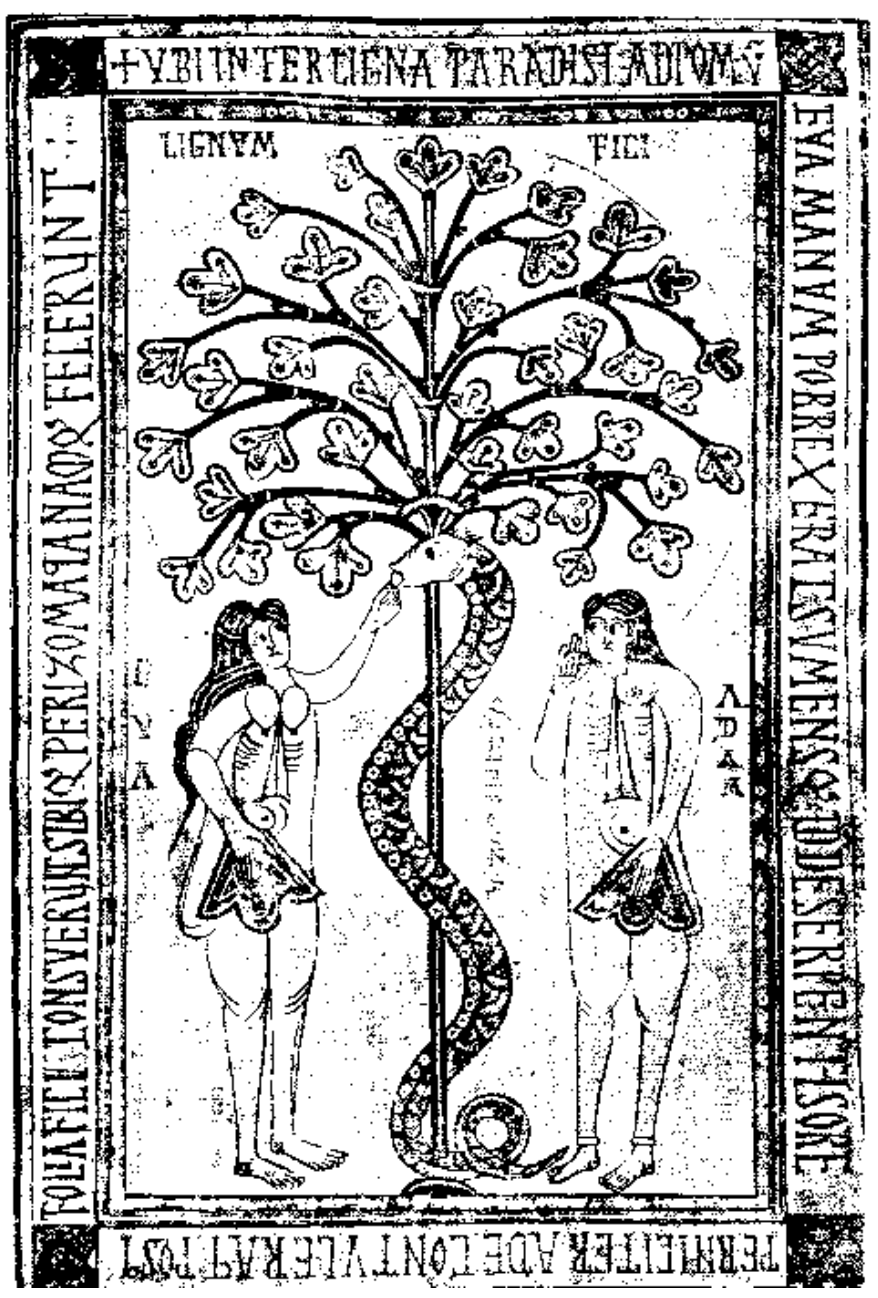

limited to the Christian religion. A M oslemillustration from 1298, taken from a Persian manuscript "Manafi al-H ayavan" (on the U sefulness of A nimals), written bylbn Bakhtishu, shows how Adam and $E$ ve are portrayed seminude, corresponding to the Seljuc (Turkish ruler of Persia from 1040) canon (DuRy, 1970). Trees in the picture are shrubs, perhaps used to displaybirds or frame the persons illustrated. The themechanged littlein an illustration from 
1307, made in Tabriz, Persia, from "Chronology of Ancient Peoples," written by alBiruni, showing the temptation. Adam and Eve are now naked, showing the Chinese influence after the $M$ ongol invasion. T rees in the composition are pomegranates ( $D u R y$, 1970).

In an illustration from the 13th century (Fig. 2a), the serpent, assuming a woman's head and upper body, gives a fruit to Eve, who in turn hands it to Adam. The illustration (Fig. 2a) is from a French manuscript from the Bibl. Nat. Paris (Didron, 1965). The emphasis isstill on the serpent, but a new element appears. The round objects that the serpent picks from the tree appear to be apples. This is perhaps the earliest illustration depicting the Tree with fruit as an apple tree.

From the middle of the 15th century the tree of Paradise appears consistently to be an appletree. About 1450, G iovanni di Paolo, of Siena, painted "The Expulsion," in which God, the Father, watches the unfortunate Adam and $E$ ve driven from Paradise ( $M$ unro, 1961). God points to a circular flat graph, the center of which depicts Paradise, represented also in detail in the background by seven fruiting apple trees.

The painting "The Fall of $M$ an," ca 1470, by H ugo van der Goes, illustrates the apples and the tree in realistic detail ( $M$ organ and Richards, 1993). In another illustration by J.J. du Pre, "H eurs a l'usage de R ome," during the same period, in 1488, Adam and $E$ ve are driven from the $G$ arden by an Angel with asword (Fig. 2b) (Prest, 1981). Thetree appears to be an apple tree with stylistic leaves, but apple-like fruit.

The appearance of the tree was further refined in a 1493 woodcut by Albert Dürer, from Ritter von Turn (Fig. 2c). The tree under which Adam and Eve stands is clearly an apple tree, and, in a typical D ürer fashion, an excellent illustration of plants (BaringGould, 1994). Other paintings of Dürer, Cranach's (1472-1553) "Adam and Eve," and Titian's (1477-1576) "Adam and Eve," all depict the Tree as apple.

The apple theme continued into the 16 th century. The Father, the $C$ reator, creating Eve from the rib of Adam under an apple tree, is seen in a stained glass window of the church St Madeleine de Tyroyes, France (D idron, 1965). A 16th-century Polish tapestry, depicting God, Adam, and Eve, and Rubens' (1577-1640) painting "The H oly Family under the Apple Tree," clearly shows the Tree as apple. In an illustration in the writing of Ludolphus of Saxonia, "Leven J hesu Christi," from 1503 (Fig. 3a), God inducts $A$ dam and $E$ ve, who walk in step into the $\mathrm{G}$ arden of Eden (Prest, 1981). The emphasis is on the fountain of life and the four

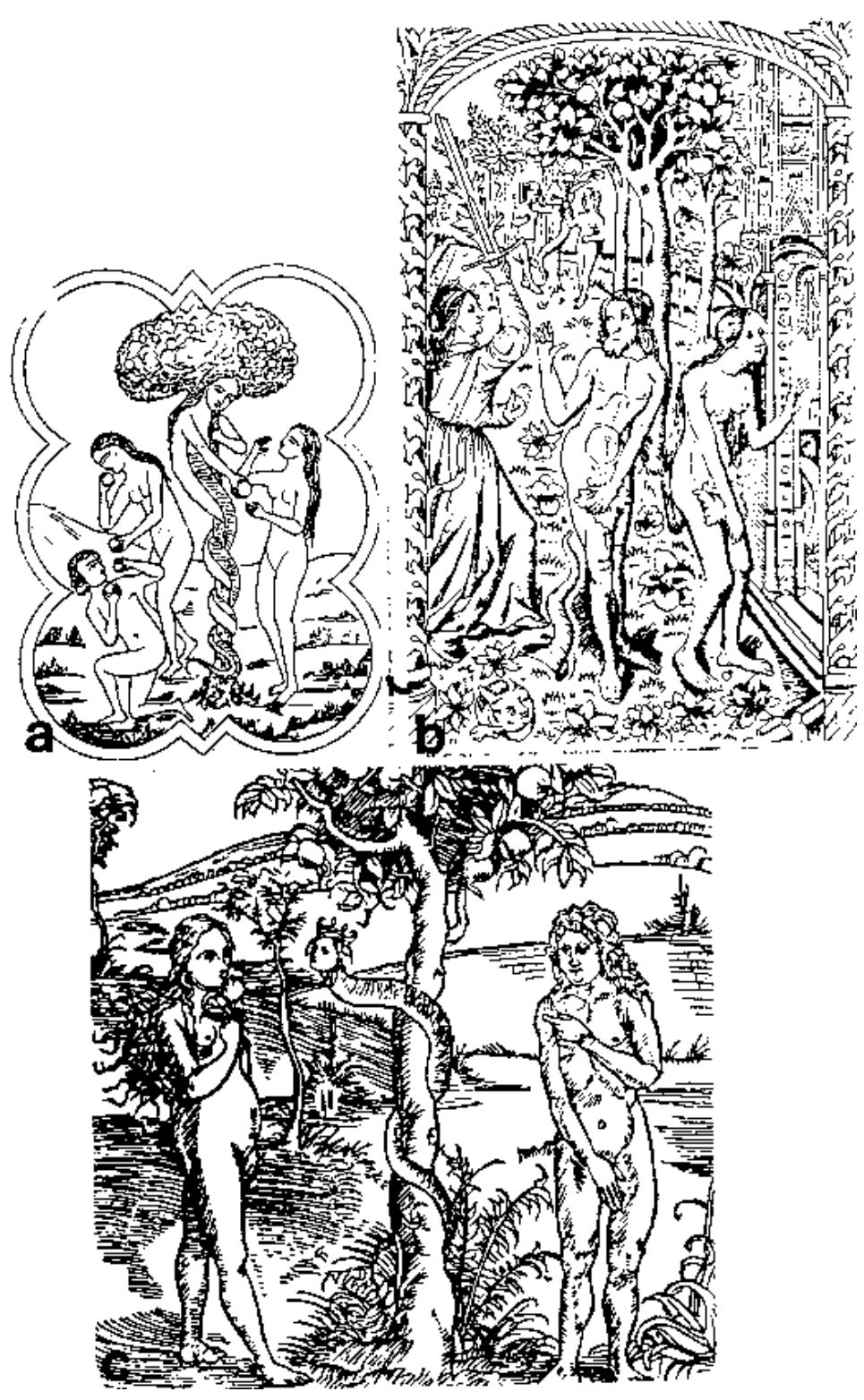

rivers issuing from the enclosing wall. The Four Rivers of Life is an ancient image of Paradise (U nderwood, 1950). TheFour Rivers also appear in the $V$ edas of ancient I ndia and in Genesis (2:10-14). The two trees in the picture appear to be apple.

In an early 16th-century scene, from 1510 , the "Fall and Expulsion" areillustrated in the same composition in the work of J.P. Bergomensis, "Suma detodaslascronicasdel mundo" (Fig. 3b). O n oneside of the composition the serpent is tempting Eve, while on the other side the angel is driving Adam and Eve out of Paradise. The Garden of Eden is conceived as a flowery meadow, containing an apple tree (Prest, 1981).

The two-tree motif returned in a typical temptation scene from 1635 (Fig. 3c). There is a palm tree in the background, presumably representing the Tree of $L$ ife, and an apple tree, intended to represent the T ree of K nowl-
Fig. 2. (a) A 13th-century illustration with an apple tree (b) Adam and Eveare driven from the $G$ arden by the Angel. (c) Woodcut by Durer. 

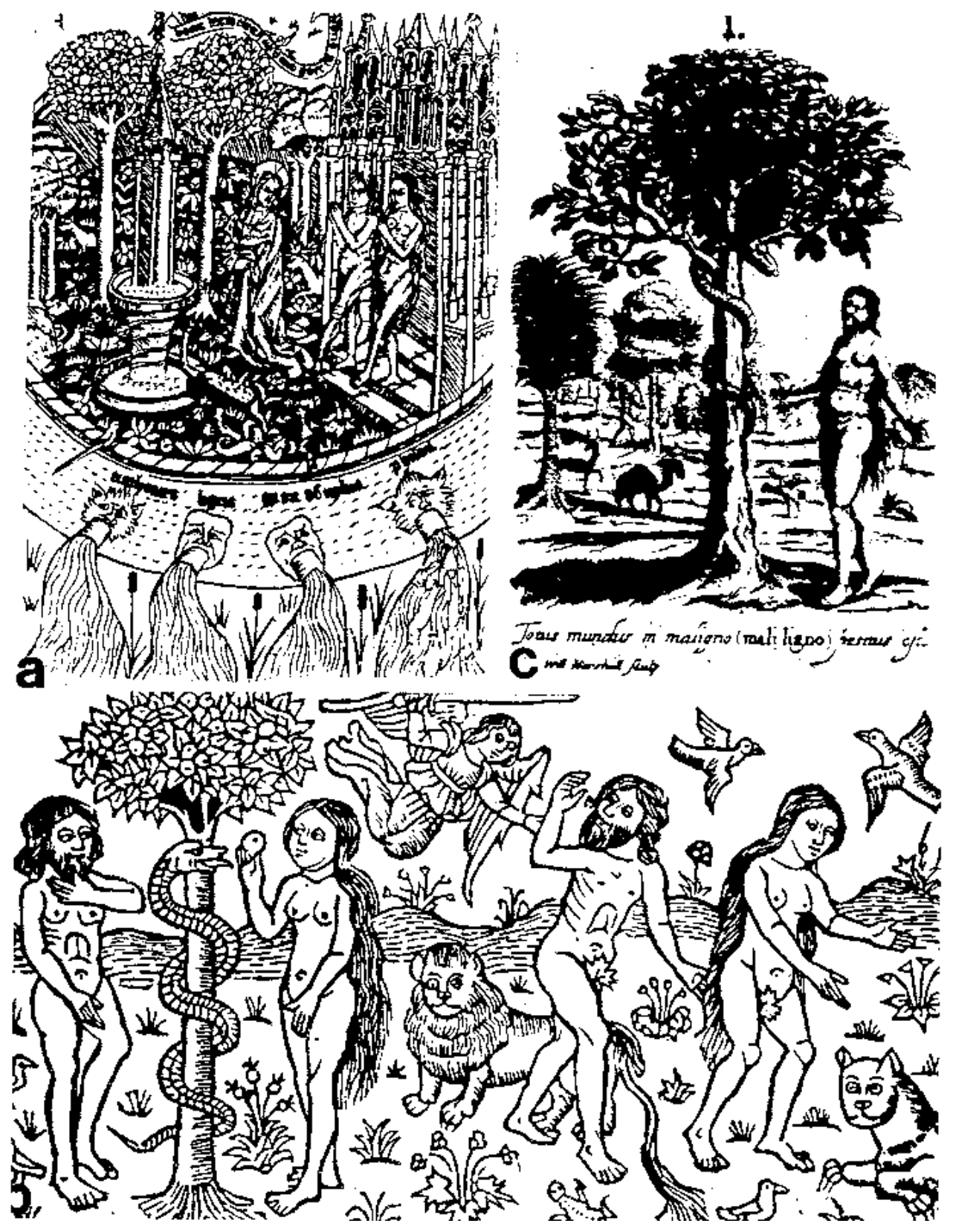

"Paradis in sole" (1629) (Fig. 4) fully reflects this view. Although in the middle of the picture there is an apple tree and in the background a Scinthian lamb, signifying that this is Paradise, the picture reflectsacollection of plantspossible only in a botanical collection-not a natural setting. The setting is nontraditional, reflecting the botanist's view. Adam is illustrated pruning a tree and Eve picking strawberries (Fig. 4).

\section{C onclusion}

When comparing illustrations available on the subject of Paradise, there is a definite break that occurs in the 13th century. Before the 13th century, the tree of Paradise is a nondescript tree, and the emphasis is on the serpent. After the 13th century, the tree is an apple tree. Why this change occurred we only can speculate. There were several events that occurred prior to the occurrence of appleas theT ree of Paradise. Previous to the 12th century, apples of northwestern E urope were small and primarily used for cider. Although the R omansintroduced largerfruited cultivars, and Charlemagne in 800 described ' $G$ eroldinga', 'C revadella', and 'Spirania' as perfumed apples, cultivation of large-fruited specimenswaslimited until the 12th century (M organ and Richards, 1993). The main impetus for the renewed culti-

Fig. 3. (a) God inducts A dam and Eveinto the Garden of Eden. (b) Fall and Expulsi on. (c) Illustration from F. Quarles "E mblemes." edge. The illustration is from F. Quarles, "Emblemes" (Prest, 1981).

The first botanic gardens opened during the 16th century. Three of these gardens, Padua, Leyden, and M ontpellier, were open in the 16th century, and three more, 0 xford, Jardin du Roi at Paris, and U ppsala, in the 17 th century. The great age of botanic gardens in the 16th century was interpreted by someastherecreation of the earthly Paradise, or the $G$ arden of $E$ den. By bringing all kinds of plantsto gether, presenting them in ahighly aesthetic arrangement, the botanic gardens were viewed as gardens creating a pleasant feeling that must have been experienced by $A d a m$ and $E$ ve in the $G$ arden of $E$ den (Prest, 1981). The cover picture of J ohn Parkinson's vation of apples came from the expansion of the Cistercian order of monks (the order was established in 1017), who valued manual labor and the cultivation of abbey lands. Apples followed the abbeys, and perhaps applebecamethe fruit of choicein Franceand Germany. About the same time, the word "Paradise" was included in the middle English in 1175, and probably with it came the concept of a lush garden, much like the abbey's gardenswhere the tree was the apple. Probably for these reasons, the apple tree became the subject of illustrators concerned with Paradise. N evertheless, we know only where and when the use of the apple as the $T$ ree of Paradise began, but we do not know the reasons why. 


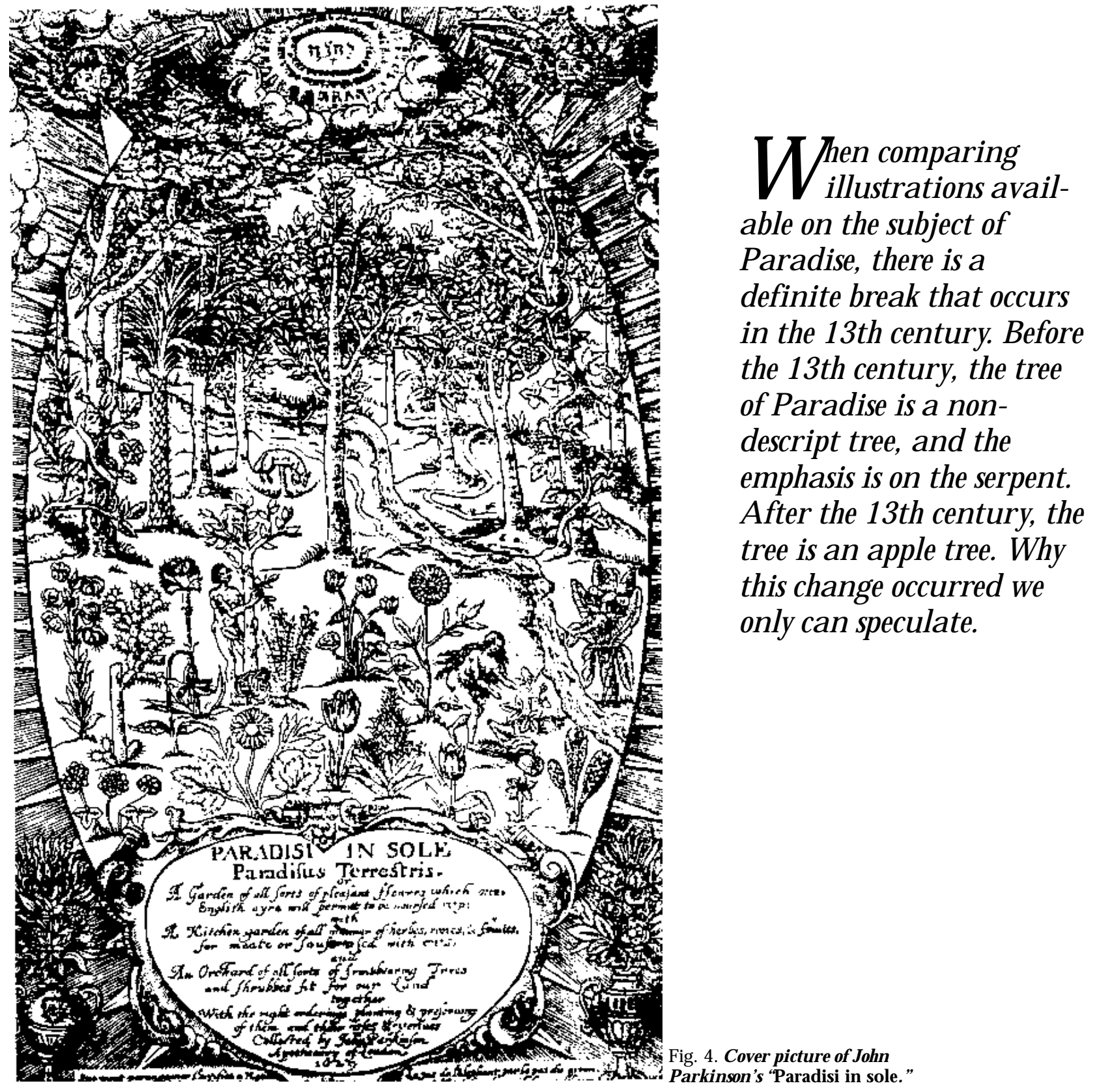

\section{L iterature C ited}

Baring-Gould, S. 1866. Curiousmyths of themiddle ages. E. H ardy (ed.) new ed. 1994. Barnes \& N oble, N ew York.

Barondes R . deR ohan. 1962. Garden of the gods, M esopotamia 5,000 B.C. p. 195-196. Boston.

Cirlot, J.E. 1962. A dictionary of symbols. Transl. from Spanish. Philosophical Library, N ew York.

Didron, A .N . 1965. Christian ichnography. vol. 2. Frederick U ngar Publ., N ew York.

Du R y, C.J. 1970. Art of I slam. H arry N. Abrams, $\mathrm{N}$ ew York

Grabar, 0. 1959. The U mayyad D ome of Rock in J erusalem. Ars 0 rientalis 3:33-62.

K nappe, A .H . 1952. La G enése des mythes. Paris. Kramer, S.N. 1956. From the Tables of Sumer.
Indian H ills, Colo. p.195-196.

Lord, C. 1970. Xenophon, The O economicus. Xenophon's Socratic discourse, an interpretation of theO economicus. L Strauss, London. p. 19-22

Morgan, J. and A. Richards. 1993. The book of apples. Ebury Press, London.

M oynihan, E.B. 1979. Paradise as a garden in Persia and M ughal India. G. Braziller, N ew York. p. 4-5.

M unro, E.C. 1961. Theencyclopediaof art. Golden Press, N ew York.

Oxford English Dictionary,.1933. vol. VII. 1933.

The word paradise.

Prest, J. 1981. The Garden of Eden. Yale U niv. Press, $\mathrm{N}$ ew $\mathrm{H}$ aven, Conn.

U nderwood, P. 1950. The fountain of life in manuscripts of gospels. D umbarton 0 ak Papers V:4148. 